\title{
Maritime Education Training Assessment Based Electronic Chart Display and Information System
}

\author{
Sun Yang*, Peng Xinya, Ding Zexuan \\ Merchant Marine College, Shanghai Maritime University, Shanghai, China \\ Email address: \\ yangsun@shmtu.edu.cn (Sun Yang), yassicapeng@163.com (Peng Xinya),348573738@qq.com (Ding Zexuan) \\ ${ }^{*}$ Corresponding author
}

To cite this article:

Sun Yang, Peng Xinya, Ding Zexuan. Maritime Education Training Assessment Based Electronic Chart Display and Information System. Advances in Applied Sciences. Vol. 5, No. 2, 2020, pp. 28-34. doi: 10.11648/j.aas.20200502.12

Received: April 9, 2020; Accepted: April 27, 2020; Published: May 14, 2020

\begin{abstract}
By the amendment adopted at MSC 86, ECDIS (Electronic Chart Display and Information System) has become mandatory for most ships from 2012. Every deck officer must be familiar with the operation of ECDIS. According to the STCW amendment, Training requirements, both in the use of ECDIS, in general and the specific models onboard, are increasing. Basically, every maritime education training institute will offer ECDIS training with simulators. Training statistics in China are shown in this paper. With the emergence of new concepts and situations, ECDIS training faces different challenges from the training results, new technology, new content and maritime cybersecurity, such as 3D ECDIS, ECDIS modernization, VR technology, and COC (Certificate of Competency) revalidation. This paper assesses the general situation of Maritime Education and Training (MET) in China, especially the ECDIS simulator training. Traditional applications of ECDIS are listed including AIS, VTS, anti-collision, pilotage and ship management. To handle these challenges, this paper presents the countermeasures respectively. The concept "MET collaboration/union" and "MET Cloud" are proposed for the first time. At the same time, this paper suggests all MET institutions should use the unified ECDIS training textbook and keep it updated to meet the challenges. The measures of cybersecurity free are also mentioned, including referring to relevant international and industry standards and best practices. Totally, the final aim is to improve and enhance the outcomes of ECDIS training for safe and efficient navigation on board.
\end{abstract}

Keywords: STCW, ECDIS Training, MET Assessment, Challenges and Countermeasures

\section{Introduction}

ECDIS is another huge technological revolution in navigation since the advent of radar and ARPA. It has grown into a new type of ship navigational system and second decision-making system on board. It can not only continuously give the position of the ship, but also support the supply of all kinds of information related to navigation. It has the characteristics of high efficiency and reliability in the function of guarding against various dangerous situations. With the gradual improvement of statutory electronic charts in various countries, the emergence of formal ECDIS and the recognition of IMO, its technological innovation has kept pace with the times and has become an important information system for ship safety.

ECDIS should be successively fitted on different categories of ship types and sizes to meet the regulation of
International Convention on the Safety of Life at Sea (SOLAS) Chapter V Regulation 19.2.10 from 1 July 2012 to 1 July 2018. The STCW, as amended in 2010 (STCW 2010) mandates that any marine officer keeping a navigational watch on any SOLAS vessels where an ECDIS is fitted must be trained and certified as competent in the use of ECDIS to maintain safe navigation.

ECDIS training has been conducted successfully by MET institutions more than ten years during the transitional period around the world. More and more competent seafarers can navigate the ship safely using ECDIS. With the occurrence of new technology and new problems with ECDIS and nautical charts, after completion of the transitional period, there are new challenges for MET based on ECDIS simulator. This paper assesses the results and details of MET based ECDIS simulator. 


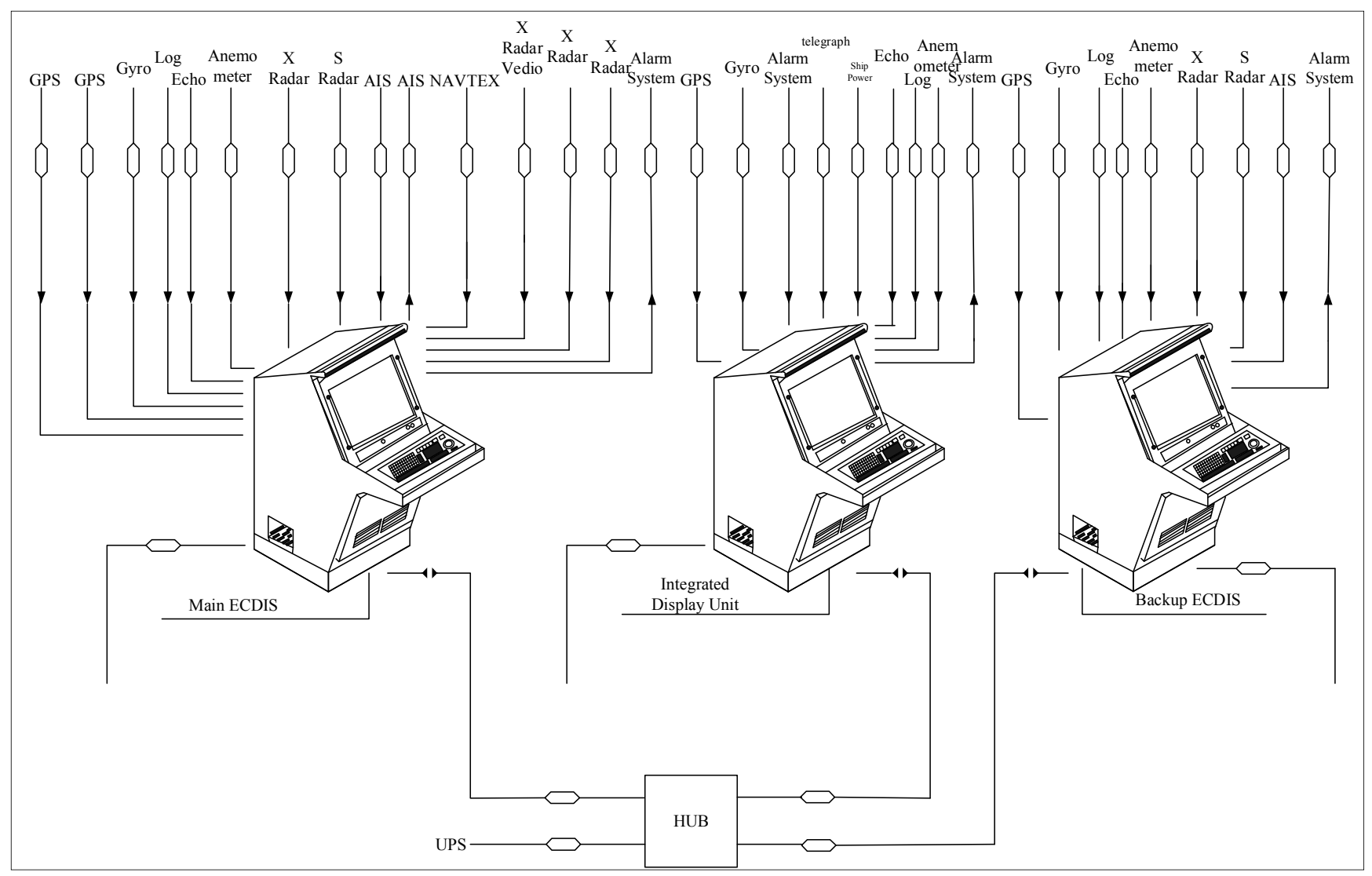

Figure 1. ECDIS Framework Diagram.

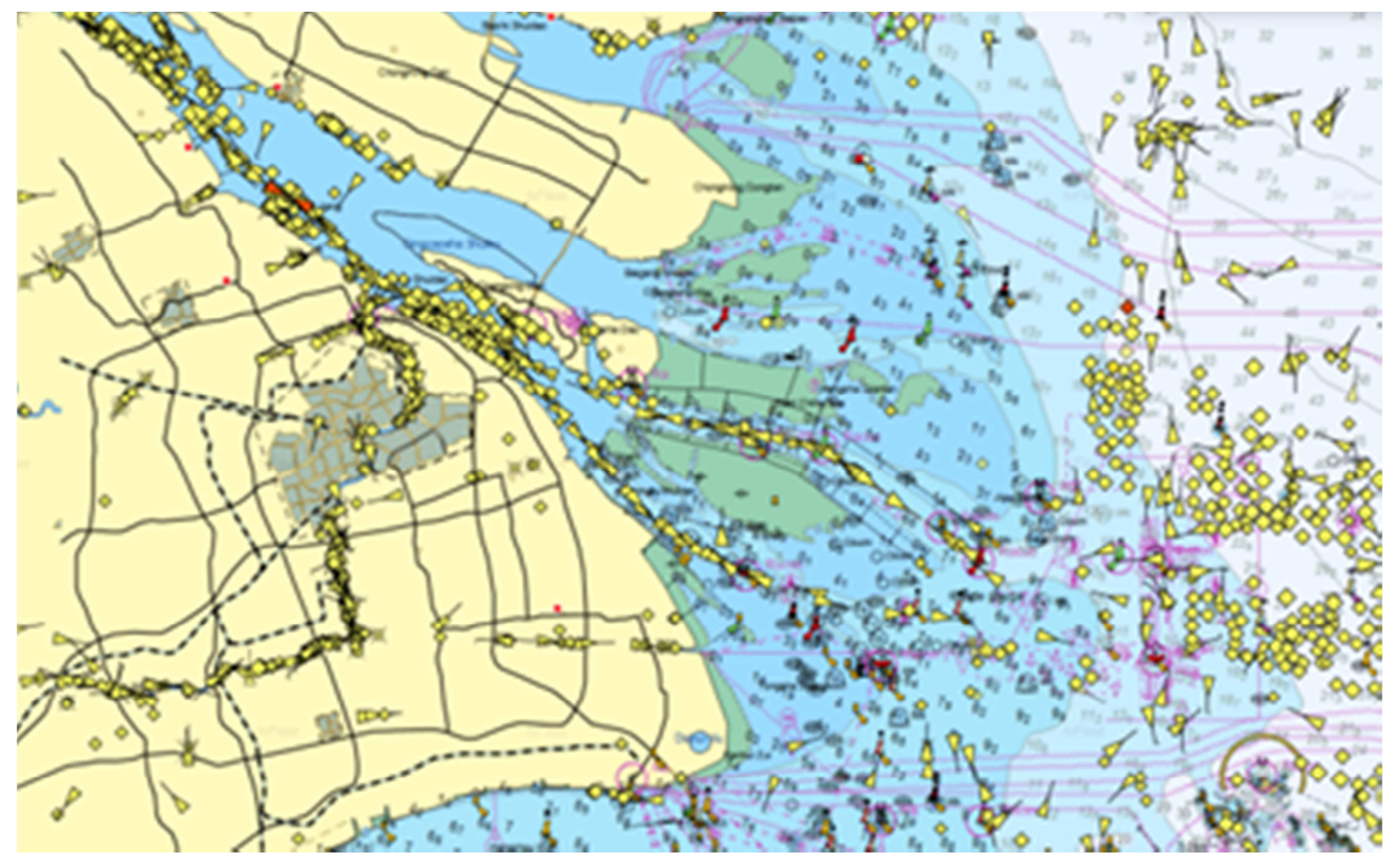

Figure 2. Electronic Chart with AIS information (Source: www.hifleet.com). 
The fundamental functions of ECDIS includes ENC display, chart work, chart corrections, positioning and navigation, nautical information display, Radar information Overlay, route monitoring and voyage record according to IMO and IHO requirements. Besides these fundamental functions, ECDIS plays an important role in shipping industry as the navigational information system. Traditionally, it can be used in the following applications during shipping operations [1].

Application in AIS: Automatic Identification System (AIS) can periodically transmit and receive ship static information (such as ship IMO number, ship nationality, call sign, ship name, etc.), dynamic information (such as ship position, speed to ground, course to ground), Sailing status, etc.) and other information related to the ship (such as the ship's draft, the type of dangerous goods, etc.). All ships equipped with AIS can receive this information and display it on ECDIS. AIS can provide the real-time traffic and relevant information to all ships which sail around the own ship to avoid ship collisions and improve the efficiency of search and rescue (SAR) operations at sea. The electronic chart overlying AIS information can improve the visibility and movement of all ships to solve the deficiency of AIS which has bad signal under the covered waters and bad weather.

Application in VTS: The emergence of ECDIS makes VTS (Vessel Traffic Service) more digital and intelligent. VTS monitoring station can display all ships' position and movement on ECDIS and query the static and dynamic conditions of the ships sailing in the VTS administration waters to the communication quality in narrow water channel.

Application in anti-collision: ECDIS can not only provide chart information (depth, seabed, dangerous isolation, offshore distance, etc.) and navigational information (own ship position, course, speed, etc.), but also can provide the dynamic information (target heading, speed, bearing, distance, CPA and TCPA, etc.) of the targets. Therefore, ECDIS can be used to check the feasibility of the collision avoidance plan.

Application in pilotage: harbor pilots always use the PPE (Portable Pilot Equipment) to manoeuvre the incoming vessel. In fact, the PPE is a navigation terminal based electronic chart display unit combining the sensor data from GPS, Gyro, VHF, GSM and communication unit, etc.

Application in ship management: shipping companies can display and plot all belonged ships on ECDIS to check their dynamic information and adjust company's plan.

\section{New Challenges}

\subsection{Challenges from Training Results}

Training is one of the key elements in regards to ECDIS compliance. Basically, there are two components which make up training. ECDIS regulations require that the master and all watch-keepers on ECDIS-fitted ships are trained in both generic and "type specific" or familiarization ECDIS training [8].

(1) Generic Training - This should follow the IMO model course 1.27 (40 hours duration) for bridge officers to satisfy the STCW.

(2) Type Specific / Familiarization Training - equipment or type specific training for a particular make and model of ECDIS needs to be carried out according to the IMO's International Safety Management (ISM) Code.

Nowadays, there are many MET institutions in the world and they conduct both generic training and type specific training towards officers and students. Taking china as an example, in order to fully and effectively implement the STCW 2010, China's Ministry of Transport developed and issued the latest Code of Competence Examination and Certification for Seafarers serving on Sea-going ships at the end of 2011.

The Ministry of Transport of the People's Republic of China issued the "Report on China Seafarer Development 2018" in June. 2019 [2]. The report showed the statistics of the development of the seafarer in China. According to the report, in 2018, China's maritime education and training (MET) institutions enrolled 16,988 students, including 9,248 in navigation and 7,750 in marine engineering (including electrical and electronic students). The data increased by $32.8 \%$ year-on-year.

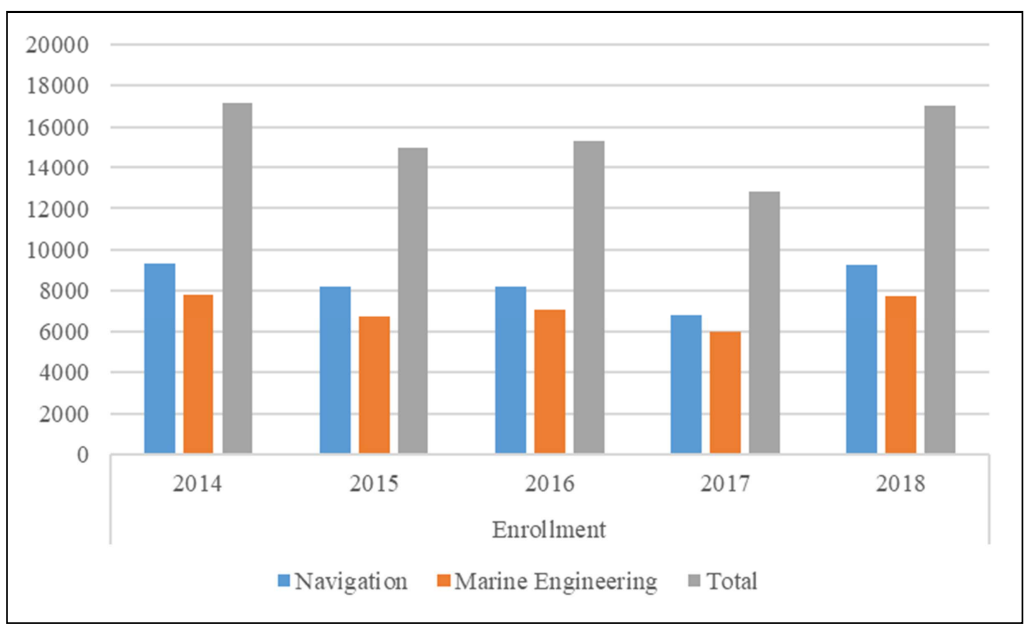

Figure 3. Histogram of Enrollment of marine students in MET institutions in China from 2014-2018. 
Table 1. Enrollment of marine students in MET institutions in China from 2014-2018 (Unit: Person).

\begin{tabular}{llllll}
\hline \multirow{2}{*}{ Major } & Enrollment & & & & \\
\cline { 2 - 6 } & $\mathbf{2 0 1 4}$ & $\mathbf{2 0 1 5}$ & $\mathbf{2 0 1 6}$ & $\mathbf{2 0 1 7}$ & $\mathbf{2 0 1 8}$ \\
\hline Navigation & 9321 & 8193 & 7229 & 6844 & 9248 \\
Marine Engineering & 7832 & 6767 & 106 & 5959 & 7750 \\
Total & 17153 & 14960 & 15335 & 12803 & 16998 \\
\hline
\end{tabular}

Besides, in 2018, there are 9,284 qualified competence training for captains and offices have been completed. Rank categorical statistics see the following table.

Table 2. Qualified Competence Training Statistics for senior officers.

\begin{tabular}{lllllll}
\hline Rank & Master & C/O & 3/O & C/E & 4/E & 3017 \\
\hline 2015 & 1914 & 3487 & 76 & 1830 & 1496 & 2813 \\
2016 & 1858 & 3268 & 104 & 161 & 23 & 2561 \\
2017 & 1798 & 2809 & 220 & 1647 & 2493 \\
2018 & 1959 & 2852 & & 113 \\
\hline
\end{tabular}

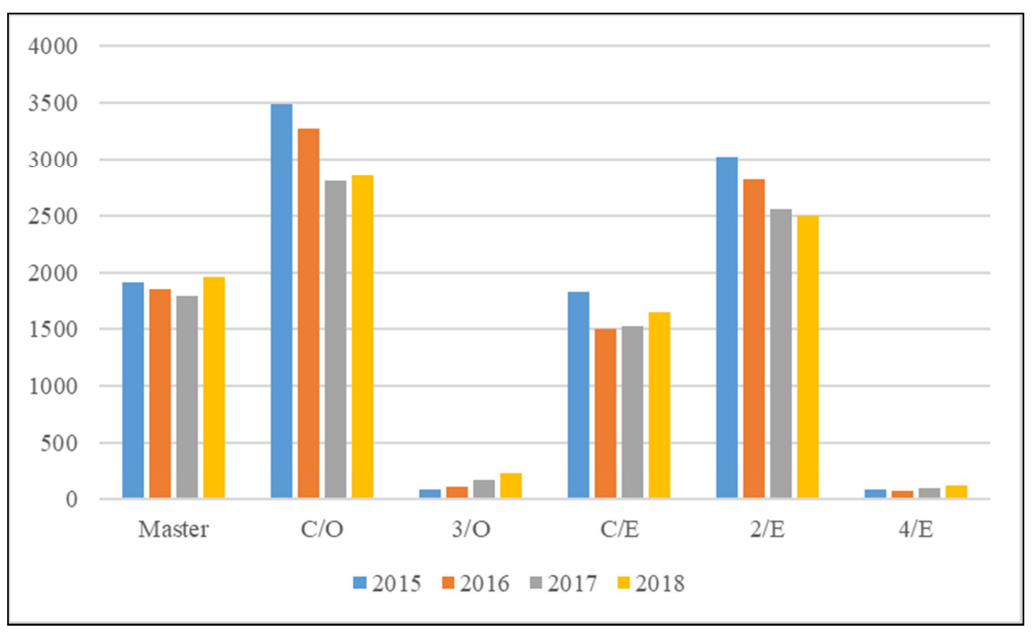

Figure 4. Qualified Competence Training Statistics.

In above statistics, all deck officers should be trained and passed the training exam about ECDIS. All competent instructors followed the regulation issued by administration to train officers and students about ECDIS. As one of the competent instructors, I experienced many trainees and ship owners or operators these years and found that most employers are not so satisfied with ECDIS training due to some facts as follows:

There are many trainee candidates about ECDIS every year around the world.

Some ECDIS simulators are outdated and impractical on generic training.

Different MET institutions' ECDIS simulators are separate and different at a global scale even in China.

Type specific training is limited to new brand or new type ECDIS equipment and depended on different watch-keepers employed different ships. The duration of training is commonly 1-2 days and just covers general function for specific type.

\subsection{Challenges from New Technology}

With the development and emergence of new technology, some changes happened on maritime education training field.
Three groups of trends in simulation are summarized in the Lloyd's Register Report "Global Maritime Trends 2030" [3][4]. One of the three trends is Technologies. Technical capabilities of shipping industry development and evolvement of simulators production.

\subsubsection{Web-based E-learning Training}

"Web-based learning (WBL) is the confluence of three social and technical developments: distance learning, computer-convoyed education, and internet technologies" says Horton. Understanding that, any MET institute can use WBL to draw student's attentions to new educational technologies putting them on the road of self-paced education that awaits them after graduation [5]. WBL will shock existing class-based ECDIS training. It is more flexible, more effective and cost-saving. Main advantages in any WBL is that it is "online", it means that learning programs can carry more than a normal media would, and that materials are constantly available and updated. On line training is the future.

Navigation is a practical science and most knowledge and experience should be obtained from practice. If ECDIS is proceeded via WBL technology, there must be some new challenge to encounter for all the relevant parties. 


\subsubsection{D Navigational Charts and Virtual Reality Simulator}

With the development of 3D navigational charts and virtual reality (VR), some ECDIS manufacturer has planned and researched to produce new model ECDIS using 3D navigational charts and VR technology.

An Electronic Navigational Chart (ENC) is a two-dimensional abstraction and generalization of the real world and it limits users' ability to obtain more real and rich spatial information of the navigation environment. However, a three-dimensional (3D) chart could dramatically reduce the number of human errors and improve the accuracy and efficiency of maneuvering. Thus it is important to be able to visualize charts in 3D. Automotive Intelligent Chart (AIC) 3D ECDIS can support global spatial data and 3D visualization, which merges the $2 \mathrm{D}$ vector electronic navigational chart with the three-dimensional navigation environment in a unified framework and interface, and is also published on the web to provide application and data service through the network [6].

$\mathrm{VR}$ is a computer technology that replicates an environment, real or imagined, and simulates a user's physical presence and environment to allow for user interaction. Virtual realities artificially create sensory experience, which can include sight, touch, hearing, and smell.

Most up-to-date virtual realities are displayed either on a computer monitor or with a virtual reality headset (also called head-mounted display), and some simulations include additional sensory information and focus on real sound through speakers or headphones targeted towards VR users.

VR can be used in new generation ECDIS simulator to provide a more visually efficient chart display system. This system can provide both global and local 3D visualization services for navigation to show artificially the real navigation environment to seafarers and students.

\subsubsection{Better Modeling Algorithms}

More and more experts and scholars focus on modeling algorithms to optimize the simulation. These algorithms can improve some process or function for ECDIS and its simulator for MET.

\subsection{Challenges from New Contents for Ecdis Training}

New contents for ECDIS training refer to new requirements and equipment including:

Regulated training:

International requirements for the seafarer's training / certification and state-of-the-art ship equipment: New edition of STCW (for meeting the requirement of COC revalidation), New edition of IMO Model Courses, New IMO performance standards for ship borne equipment, New edition of IEC 61174.

Non-regulated training:

Most frequent requirements from simulator users based on their customer requests, their own experience and industry development.

New contents also influent the MET based on ECDIS simulator. The training syllabus should be adapted to emerging changes. For example, IMO has adopted the International Code for Ships Operating in Polar Waters (Polar Code) and related amendments to make it mandatory under both the SOLAS and the International Convention for the Prevention of Pollution from Ships (MARPOL). The administration and MET institution must add the ice/polar navigation instruction among the training.

Another example is on ECDIS data format. S-57 is the ENC chart data format defined by IHO Transfer Standard for Digital Hydrographic Data. Majority of ECDIS use S-57 format now and it will be replaced or compatible with S-101. S-101 is a new Product Specification for the Electronic Navigational Chart [7].

ECDIS training will also encounter new challenges from new applications, such as, ECDIS usage in Search and Rescue (SAR) operation, usage in Dynamic Positioning (DP) and usage in polar waters navigation [9].

\subsection{Challenges from Maritime Cyber Security}

According to the Guidelines on maritime cyber risk management $[10,12]$, maritime cyber risk refers to a measure of the extent to which a technology asset is threatened by a potential circumstance or event, which may result in shipping-related operational, safety or security failures as a consequence of information or systems being corrupted, lost or compromised.

Smart ships are listed as one of the key trends in the future shipping and maritime field as per reports of most research institutions. With the deepening of the informationization and intelligence of shipping industry and the implementation of E-Navigation, IMO has paid more attention to maritime cyber security from shore-based facilities to the entire shipping field. Undoubtedly, intelligence has bought tremendous chance and convenience to shipping industry. However, the cyber security also will pose great challenges to the future development of the shipping and maritime industry.

ECDIS is one of the core navigation equipment of intelligent ships and plays a vital role in the safe navigation of ships. If the ECDIS equipment is attacked by the network, ship casualties such as ship collision, stranding, and reef collision will seriously affect navigation safety. In addition to formulating a series of norms and standards to ensure ship security, the shipping industry should also train and understand the means and measures of ECDIS to deal with cyber-attacks on crew training from the perspective of MET, and popularize the knowledge of maritime network security and Specific countermeasures on professional navigation equipment such as ECDIS.

\section{Countermeasures}

At present, most maritime education training based on ECDIS simulator all over the world is traditional and classic. Take China as an example, all MET institutions will be or are encountering all challenges above mentioned. In my 
institution, ECDIS simulation training has been utilizing the old simulator developing in 2012 and it doesn't include the new contents and doesn't use the new technology. Some examination during the ECDIS training still adopt the paper form and some questions are graded manually instead of automatically.

To cope with the challenge of training result, new technology and new contents, some countermeasures should be taken and considered [11].

\subsection{ECDIS MET Institution Collaboration/Union}

Global collaboration between MET institutions is a better way to cope with all challenges. Constant and regular training can offer the required type-specific familiarization for all ECDIS models combined with a sophisticated interactive teaching method for real hands-on familiarization.

Seafarer is an international career due to the nature of the shipping industry. Globalization is the most outstanding features for seafarer. Before being on board as a deck officer, all trainees should be accepted the best education and training for navigation skills including ECIDS simulator training. All involved institutions should try their best to find a new way to train the students to really grasp and understand the meaning and operation of the ECDIS.

\subsection{ECDIS MET Cloud}

New technology is the motivation and trend of ECDIS simulator development. Can simulators be run from the real to the "Cloud"? Cloud is the development tendency for maritime field using the latest IT. The training model will be advanced and synchronous if the "Cloud" is on line to cope with the fast-changing technology.

\subsection{ECDIS MET Textbook}

To cope with new contents challenge, ECDIS simulator should keep products and systems in line with changes in STCW and new IMO Model Courses to ensure that all relevant courses may be conducted in simulators in accordance with the latest STCW amendments. Maintain proactive contact with local authorities and ensure compliance with both local and international standards. The ECDIS MET institution collaboration/union mentioned in 3.1 should paly a leading role in drafting the unified ECDIS MET textbook and keep it updated to all MET institutions around the world.

Furthermore, the textbook should not only keep the knowledge update but also stay the contents always leading-edge in shipping field, such as ECDIS application in DP operation and SAR operation etc.

\subsection{Cyber Security Free}

Cyber security knowledge is essential for maritime education training in the future [13]. ECDIS as the core element in smart ship, MET institution must coach how to protect the ship from cyber security. The approach to cyber risk protection on ECDIS provides a foundation for better understanding and managing cyber risks, thus enabling a risk management approach to address cyberthreats and vulnerabilities. All instructors in MET institution should refer to relevant international and industry standards and best practices, including IMO guidelines, ISO/IEC standards and NGO's guidelines related to cyber security.

\section{Conclusion}

ECDIS will take more and more important role in safe navigation in the future. It takes the task for integration and interaction between different sensor information. Maritime education training based on ECDIS simulator have the responsibility to train the seafarers and students with the competency to handle with the new coming technologies and changes all over the world. Find a better way and establish mechanism to achieve the comprehensive solution simple to reconfigure and operate at a long-term scale.

\section{References}

[1] Ren S-TC, Xue-Feng. The function and application of ECDIS. Journal of Guangzhou Maritime College. 2005; 13 (1): 15-7.

[2] The Ministry of Transport of the People's Republic of China. Report on China Seafarer Development 2018. 2019.

[3] Lloyd's Register Report, "Global Maritime Trends 2030".

[4] Transas Report, "Future trends and new challenges in maritime simulation".

[5] AMR, M. I. and AHMED, K. T. Educational technology in MET simulator based training and information technology in MET. International Journal of Mechanical Engineering (IJME). Vol. 4, Issue 3, Apr - May 2015, 1-10.

[6] Liu, T, Zhao, D. P., Pan, M. Y. Generating 3D Depiction for a Future ECDIS Based on Digital Earth. THE JOURNAL OF NAVIGATION (2014), 67, 1049-1068.

[7] IHO S-100. Universal Hydrographic Data Model. Edition 1.0.0. International Hydrographic Organization, Monaco (2010).

[8] Chen, Y. L. and Xiao, Y. J. ECDIS Training in China: from International to National. Proceedings of the 13th Annual General Assembly of the IAMU. 2012, pp. 35-41.

[9] International Maritime Organization. NCSR 7-22-5 - Report on monitoring of ECDIS issues by IHO (IHO). NSCR Committee. 2019.

[10] http://www.imo.org/en/OurWork/Security/Guide_to_Maritime _Security/Pages/Cyber-security.aspx.

[11] Zhang Y-PC, Yu-Chi; Zhang, Ji-Ping. ECDIS simulator education and training: demand, problem and countermeasures. Navigation Education Research. 2020; 37 (1).

[12] International Maritime Organization. MSC-FAL. 1-Circ. 3 Guidelines On Maritime Cyber Risk Management (Secretariat). MSC Committee. 2017.

[13] Wu X-FX, You. Marine Cyber Security: Cross-border challenges of shipping and shipping industry. China Ship Survey. 2017. 
[14] Society CC. Guidelines for Survey of Electronic chart display and information system (ECDIS). CCS Guidance Notes. 2012.

[15] Kastrisios C, Pilikou M. Nautical cartography competences and their effect to the realisation of a worldwide Electronic Navigational Charts database, the performance of ECDIS and the fulfilment of IMO chart carriage requirements. Marine Policy. 2017; 75: 29-37.

[16] Kavallieratos G, Diamantopoulou V, Katsikas S. Shipping 4.0: Security requirements for the Cyber-Enabled Ship. IEEE Transactions on Industrial Informatics. 2020: 1-

[17] Kazimierski W, Stateczny A. Radar and Automatic Identification System Track Fusion in an Electronic Chart Display and Information System. Journal of Navigation. 2015; 68 (6): 1141-54.

[18] Liu T, Han X, Yang J, Kuang L. A Unified Indexing Strategy for the Mixed Data of a Future Marine GIS. Journal of Navigation. 2017; 70 (4): 735-47.

[19] Liu T, Zhao D, Pan M. An approach to 3D model fusion in GIS systems and its application in a future ECDIS. Computers \& Geosciences. 2016; 89: 12-20.

[20] Liu T, Zhao D-P, Pan M-Y, Bai K. Fusing Multiscale Charts into 3D ENC Systems Based on Underwater Topography and Remote Sensing Image. Mathematical Problems in Engineering. 2015.

[21] Perera LP, Soares CG. Weather routing and safe ship handling in the future of shipping. Ocean Engineering. 2017; 130: 684-95.

[22] Saravanan K, Aswini S, Kumar R, Son LH. How to prevent maritime border collision for fisheries?-A design of Real-Time Automatic Identification System. Earth Science Informatics. 2019; 12 (2): 241-52.

[23] Svilicic B, Kamahara J, Celic J, Bolmsten J. Assessing ship cyber risks: a framework and case study of ECDIS security. WMU Journal of Maritime Affairs. 2019; 18 (3): 509-20.

[24] Svilicic B, Rudan I, Jugovic A, Zec D. A Study on Cyber Security Threats in a Shipboard Integrated Navigational System. Journal of Marine Science and Engineering. 2019; 7 (10).

[25] Tam K, Jones K. MaCRA: a model-based framework for maritime cyber-risk assessment. WMU Journal of Maritime Affairs. 2019; 18 (1): 129-63.

[26] Tsou M-C. Multi-target collision avoidance route planning under an ECDIS framework. Ocean Engineering. 2016; 121: 268-78.

[27] Turna I, Ozturk OB. A causative analysis on ECDIS-related grounding accidents. Ships and Offshore Structures. 2019.

[28] Zhang X-Y, Ji M-J, Yao S, Chen X. Optimising Feeder Routing for Container Ships through an Electronic Chart Display and Information System. Journal of Navigation. 2015; 68 (5): 848-68. 